\title{
Prime Labeling in Context of Ring Sum of Graphs
}

\author{
A. H. Rokad ${ }^{1}$, G. V. Ghodasara ${ }^{2}$ \\ ${ }^{1} \mathrm{PhD}$ Scholar, School of Science, RK University, Rajkot - 360020, Gujarat, India \\ ${ }^{2}$ H. \& H. B. Kotak Institute of Science, Rajkot - 360001, Gujarat - India
}

\begin{abstract}
A graph with vertex set $V$ is said to have a prime labeling if its vertices are labeled with distinct integers $1,2, \ldots,|V|$ such that for each edge $x y$ the labels assigned to $x$ and $y$ are relatively prime. In this paper we have derived prime labeling of ringsum of different graphs.
\end{abstract}

Keywords: prime labeling, ring Sum, cycle with one chord, cycle with twin chord, cycle with triangle, shell

\section{Introduction}

Throughout this paper, a graph $\mathrm{G}=(\mathrm{V}, \mathrm{E})$ is a undirected, finite, connected, and simple graph with vertex set $\mathrm{V}$ and edge set E. For different notations and terminology we follow Gross and Yellen[2]. A survey on different graph labeling techniques is given by Gallian[1]. The notion of a prime labeling originated with Entringer and was introduced in a paper by Tout, Dabboucy, and Howalla[3]. Around 1980, Entringer conjectured that all trees have a prime labeling. Little progress was made on this conjecture until 2011 when Haxell, Pikhurko, Taraz[4] proved that all large trees are prime. Seoud, Diab, and Elsakhawi[5] have shown the following graphs are prime: fans, helms, flowers, stars. Vaidya and Prajapati[6] proved that the graphs obtained by duplication of a vertex by a vertex in $P_{n}$ and $K_{1, n}$ are prime graphs and the graphs obtained by duplication of a vertex by an edge, duplication of an edge by a vertex, duplication of an edge by an edge in $\mathrm{P}_{n}, \mathrm{~K}_{1, \mathrm{n}}$, and $\mathrm{Cn}$ are prime graphs. They also proved that graph obtained by duplication of every vertex by an edge in $\mathrm{P}_{\mathrm{n}}, \mathrm{K}_{1, \mathrm{n}}$, and $\mathrm{Cn}$ are not prime graphs. Youssef and Elsakhawi[7] have shown: the union of stars $S_{m}$ $\cup S_{n}$ are prime; the union of cycles and stars $C_{m} \cup S_{n}$ are prime; $K_{m} \cup P_{n}$ is prime if and only if $m$ is at most 3 or if $m$ $=4$ and $n$ is odd.

\section{Definition}

Definition 1. Ring sum of two graphs $G_{1}=\left(V_{1}, E_{1}\right)$ and $G_{2}=$ $\left(V_{2}, E_{2}\right)$, denoted by $G_{1} \oplus G_{2}$, is the graph, $G_{1} \oplus G_{2}=\left(\left(V_{1}\right.\right.$ $\left.\left.\cup V_{2}\right),\left(\left(E_{1} \cup E_{2}\right)-\left(E_{1} \cap E_{2}\right)\right)\right)$.

Definition 2. Let $G=(V(G), E(G))$ be a graph with $p$ vertices.

A bijection $\mathrm{f}: \mathrm{V}(\mathrm{G}) \rightarrow 1,2, \ldots, \mathrm{p}$ is called a prime labeling if for each edge $\mathrm{e}=\mathrm{uv}, \operatorname{gcd}(\mathrm{f}(\mathrm{u}), \mathrm{f}(\mathrm{v}))=1$. A graph which admits prime labeling is called a prime graph.

\section{Main Results}

Theorem 1. $C_{n} \oplus K_{1, n}$ is a prime graph for all $n \in N$.

Proof. Let $\mathrm{V}(\mathrm{G})=\mathrm{V}_{1} \cup \mathrm{V}_{2}$, where $\mathrm{V}_{1}=\left\{\mathrm{u}_{1}, \mathrm{u}_{2}, \ldots, \mathrm{u}_{\mathrm{n}}\right\}$ be the vertex set of $\mathrm{C}_{\mathrm{n}}$ and

$\mathrm{V}_{2}=\left\{\mathrm{v}=\mathrm{u}_{1}, \mathrm{v}_{1}, \mathrm{v}_{2}, \ldots, \mathrm{v}_{\mathrm{n}}\right\}$ be the vertex set of $\mathrm{K}_{1, \mathrm{n}}$. Here $\mathrm{v}_{1}$, $\mathrm{v}_{2}, \ldots, \mathrm{v}_{\mathrm{n}}$ are pendent vertices. Also $|\mathrm{V}(\mathrm{G})|=|\mathrm{E}(\mathrm{G})|=2 \mathrm{n}$.

We define labeling $\mathrm{f}: \mathrm{V}(\mathrm{G}) \rightarrow\{1,2,3, \ldots, 2 \mathrm{n}\}$ as follows.

$\mathrm{f}\left(\mathrm{u}_{\mathrm{i}}\right)=2 \mathrm{i}-1 ; 1 \leq \mathrm{i} \leq \mathrm{n}$

$\mathrm{f}\left(\mathrm{v}_{\mathrm{j}}\right)=2 \mathrm{j} ; 1 \leq \mathrm{j} \leq \mathrm{n}$

According to this pattern the vertices are labeled such that for any edge $\mathrm{e}=\mathrm{u}_{\mathrm{i}} \mathrm{u}_{\mathrm{j}} \in \mathrm{G}, \operatorname{gcd}\left(\mathrm{f}\left(\mathrm{u}_{\mathrm{i}}\right), \mathrm{f}\left(\mathrm{u}_{\mathrm{j}}\right)\right)=1$.

Thus we proved that the graph under consideration admits prime labeling.

That is, $\mathrm{C}_{\mathrm{n}} \oplus \mathrm{K}_{1, \mathrm{n}}$ is a prime graph.

Example 1. prime labeling of the graph $C_{5} \oplus K_{1,5}$ is shown in Fig. 1 as an illustration for the Theorem 1.

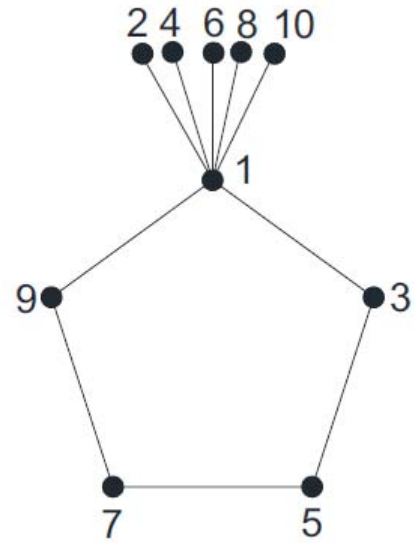

Figure 1: prime labeling of the graph $\mathrm{C}_{5} \oplus \mathrm{K}_{1,5}$

Theorem 2. $G \oplus K_{1, n}$ is a prime graph, where $G$ is cycle with one chord and chord forms a triangle with two edges of the cycle, for all $n \in N$.

Proof. Let $\mathrm{G}$ be the cycle $\mathrm{C}_{\mathrm{n}}$ with one chord. Let $\mathrm{V}=\mathrm{V}_{1} \mathrm{U}$ $V_{2}$, where $V_{1}$ is the vertex set of $G$ and $V_{2}$ be the vertex set of $\mathrm{K}_{1, \mathrm{n}}$. And let $\mathrm{u}_{1}, \mathrm{u}_{2}, \ldots, \mathrm{u}_{\mathrm{n}}$ be consecutive vertices of cycle $\mathrm{C}_{\mathrm{n}}$ and $\mathrm{e}=\mathrm{u}_{1} \mathrm{u}_{3}$ be a chord of cycle $\mathrm{C}_{\mathrm{n}}$. The vertices $\mathrm{u}_{1}, \mathrm{u}_{2}, \mathrm{u}_{3}$ forms a triangle with chord e.

Let $v_{1}, v_{2}, \ldots, v_{n}$ be the pendent vertices, $v$ be the apex 


\section{International Journal of Science and Research (IJSR) \\ ISSN (Online): 2319-7064}

Index Copernicus Value (2013): 6.14 | Impact Factor (2014): 5.611

vertex of $\mathrm{K}_{1, \mathrm{n}}$ and take $\mathrm{v}=\mathrm{u}_{1}$

Also $|\mathrm{V}(\mathrm{G})|=2 \mathrm{n}$ and $|\mathrm{E}(\mathrm{G})|=2 \mathrm{n}+1$

We define labeling $\mathrm{f}: \mathrm{V}(\mathrm{G}) \rightarrow\{1,2,3, \ldots, 2 \mathrm{n}\}$ as follows.

$\mathrm{f}\left(\mathrm{u}_{1}\right)=1, \mathrm{f}\left(\mathrm{u}_{2}\right)=3, \mathrm{f}\left(\mathrm{u}_{\mathrm{n}}\right)=5$

$\mathrm{f}\left(\mathrm{u}_{\mathrm{i}}\right)=2 \mathrm{i}+1 ; 3 \leq \mathrm{i} \leq \mathrm{n}-1$

$\mathrm{f}\left(\mathrm{v}_{\mathrm{j}}\right)=2 \mathrm{j} ; 1 \leq \mathrm{j} \leq \mathrm{n}$

According to this pattern the vertices are labeled such that for any edge $\mathrm{e}=\mathrm{u}_{\mathrm{i}} \mathrm{u}_{\mathrm{j}} \in \mathrm{G}$,

$\operatorname{gcd}\left(\mathrm{f}\left(\mathrm{u}_{\mathrm{i}}\right), \mathrm{f}\left(\mathrm{u}_{\mathrm{j}}\right)\right)=1$.

Thus we proved that the graph under consideration admits prime labeling.

That is, $\mathrm{G} \oplus \mathrm{K}_{1, \mathrm{n}}$ is a prime graph, $\mathrm{G}$ is the cycle $\mathrm{C}_{\mathrm{n}}$ with one chord.

Example 2. prime labeling of ring sum of the graph cycle $\mathrm{C}_{6}$ with one chord and $\mathrm{K}_{1,6}$ is shown in Fig. 2 as an illustration for the Theorem 2.

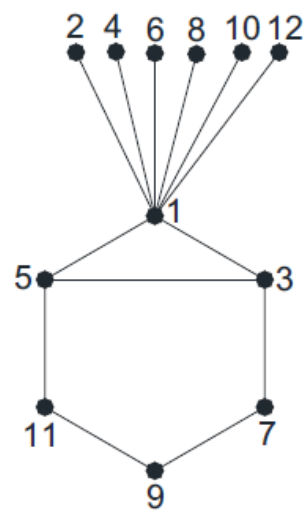

Figure 2: prime labeling of ring sum of the graph cycle $\mathrm{C}_{6}$ with one chord and $\mathrm{K}_{1,6}$

Theorem 3. $\mathrm{G} \oplus \mathrm{K}_{1, \mathrm{n}}$ is a prime graph, where $\mathrm{G}$ is cycle with twin chord and chords forms two triangles and one cycle $\mathrm{C}_{\mathrm{n}-2}$, for all $\mathrm{n} \in \mathrm{N}$.

Proof. Let $\mathrm{G}$ be the cycle $\mathrm{C}_{\mathrm{n}}$ with twin chords, where chords form two triangles and one cycle $C_{n-2}$. Let $V=V_{1} \cup V_{2}$, where $V_{1}$ is the vertex set of $G$ and $V_{2}$ be the vertex set of $\mathrm{K}_{1, \mathrm{n}}$. And let $\mathrm{u}_{1}, \mathrm{u}_{2}, \ldots, \mathrm{u}_{\mathrm{n}}$ be successive vertices of $\mathrm{G}$ and $\mathrm{e}_{1}$ $=u_{n} u_{2}$ and $e_{2}=u_{n} u_{3}$ be the chords of cycle $C_{n}$. Let $v_{1}, v_{2}, \ldots$ , $\mathrm{V}_{\mathrm{n}}$ be the pendent vertices, $\mathrm{v}$ be the apex vertex of $\mathrm{K}_{1, \mathrm{n}}$ and take $\mathrm{v}=\mathrm{u}_{1}$.

Also $|\mathrm{V}(\mathrm{G})|=2 \mathrm{n}$ and $|\mathrm{E}(\mathrm{G})|=2 \mathrm{n}+2$

We define labeling $\mathrm{f}: \mathrm{V}(\mathrm{G}) \rightarrow\{1,2,3, \ldots, 2 \mathrm{n}\}$ as follows.

$\mathrm{f}\left(\mathrm{u}_{1}\right)=1, \mathrm{f}\left(\mathrm{u}_{2}\right)=3, \mathrm{f}\left(\mathrm{u}_{\mathrm{n}}\right)=5$

$\mathrm{f}\left(\mathrm{u}_{\mathrm{i}}\right)=2 \mathrm{i}+1 ; 3 \leq \mathrm{i} \leq \mathrm{n}-1$

$\mathrm{f}\left(\mathrm{v}_{\mathrm{j}}\right)=2 \mathrm{j} ; 1 \leq \mathrm{j} \leq \mathrm{n}$

According to this pattern the vertices are labeled such that for any edge $\mathrm{e}=\mathrm{u}_{\mathrm{i}} \mathrm{u}_{\mathrm{j}} \in \mathrm{G}$,

$\operatorname{gcd}\left(\mathrm{f}\left(\mathrm{u}_{\mathrm{i}}\right), \mathrm{f}\left(\mathrm{u}_{\mathrm{j}}\right)\right)=1$.

Thus we proved that the graph under consideration admits prime labeling.

That is, $G \bigoplus K_{1, n}$ is a prime graph, where $G$ is the cycle $C_{n}$ with twin chord

Example 3: prime labeling of ring sum of the graph the graph cycle $\mathrm{C}_{7}$ with twin chords and $\mathrm{K}_{1,7}$ is shown in Fig. 3 as an illustration for the Theorem 3 .

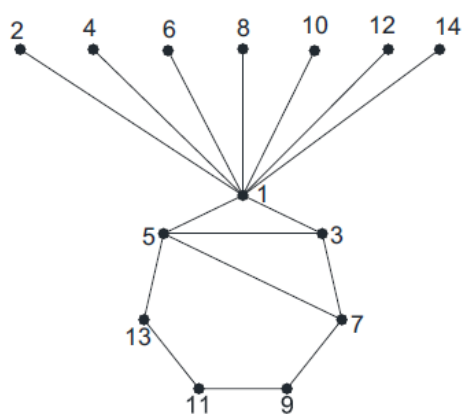

Figure 3: prime labeling of ring sum of the graph cycle $C_{7}$ with twin chords and $\mathrm{K}_{1,7}$

Theorem 4. $\mathrm{G} \oplus \mathrm{K}_{1, \mathrm{n}}$ is a prime graph, where $\mathrm{G}$ is cycle with triangle and chords forms three triangles and one cycle $\mathrm{C}_{\mathrm{n}-5}$, for all $\mathrm{n} \in \mathrm{N}$.

Proof. Let $\mathrm{G}$ be cycle with triangle $\mathrm{C}_{\mathrm{n}}(1,1, \mathrm{n}-5)$. Let $\mathrm{V}=$ $V_{1} \cup V_{2}$, where $V_{1}$ is the vertex set of $G$ and $V_{2}$ be the vertex set of $\mathrm{K}_{1, \mathrm{n}}$. And Let $\mathrm{u}_{1}, \mathrm{u}_{2}, \ldots, \mathrm{u}_{\mathrm{n}}$ be successive vertices of $\mathrm{G}$.

Let $\mathrm{u}_{1}, \mathrm{u}_{3}$ and $\mathrm{u}_{5}$ be the vertices of triangle formed by edges $\mathrm{e}_{1}=\mathrm{u}_{1} \mathrm{u}_{3}, \mathrm{e}_{2}=\mathrm{u}_{3} \mathrm{u}_{5}$ and $\mathrm{e}_{3}=\mathrm{u}_{1} \mathrm{u}_{5}$.

Let $\mathrm{v}_{1}, \mathrm{v}_{2}, \ldots, \mathrm{v}_{\mathrm{n}}$ be the pendent vertices, $\mathrm{v}$ be the apex vertex of $\mathrm{K}_{1, \mathrm{n}}$ and take $\mathrm{v}=\mathrm{u}_{1}$.

Also $|\mathrm{V}(\mathrm{G})|=2 \mathrm{n}$ and $|\mathrm{E}(\mathrm{G})|=2 \mathrm{n}+3$

We define labeling $\mathrm{f:} \mathrm{V}(\mathrm{G}) \rightarrow\{1,2,3, \ldots, 2 \mathrm{n}\}$ as follows.

$\mathrm{f}\left(\mathrm{u}_{1}\right)=1, \mathrm{f}\left(\mathrm{u}_{2}\right)=3, \mathrm{f}\left(\mathrm{u}_{3}\right)=5, \mathrm{f}\left(\mathrm{u}_{\mathrm{n}-1}\right)=7, \mathrm{f}\left(\mathrm{u}_{\mathrm{n}}\right)=\mathrm{n}$

$\mathrm{f}\left(\mathrm{u}_{\mathrm{i}}\right)=2 \mathrm{i}+1 ; 4 \leq \mathrm{i} \leq \mathrm{n}-2$

$\mathrm{f}\left(\mathrm{v}_{\mathrm{j}}\right)=2 \mathrm{j} ; 1 \leq \mathrm{j} \leq \mathrm{n}$

According to this pattern the vertices are labeled such that for any edge $\mathrm{e}=\mathrm{u}_{\mathrm{i}} \mathrm{u}_{\mathrm{j}} \in \mathrm{G}, \operatorname{gcd}\left(\mathrm{f}\left(\mathrm{u}_{\mathrm{i}}\right), \mathrm{f}\left(\mathrm{u}_{\mathrm{j}}\right)\right)=1$.

Thus we proved that the graph under consideration admits prime labeling. That is, $\mathrm{G} \oplus \mathrm{K}_{1, \mathrm{n}}$ is a prime graph, where $\mathrm{G}$ is the cycle $\mathrm{C}_{\mathrm{n}}$ with triangle.

Example 4. prime labeling of ring sum of the graph the graph cycle $\mathrm{C}_{8}$ with twin chords and $\mathrm{K}_{1,8}$ is shown in Fig. 4 as an illustration for the Theorem 4 .

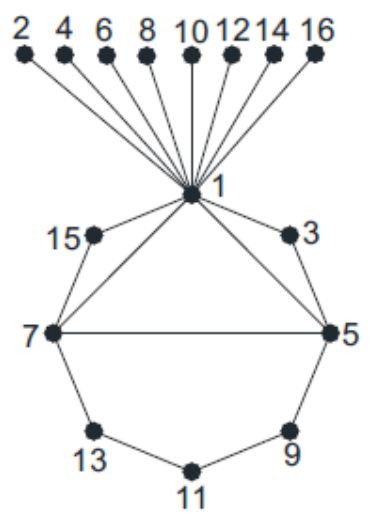

Figure 4: prime labeling of ring sum of the graph cycle $C_{8}$ with triangle and $\mathrm{K}_{1,8}$

\section{Volume 4 Issue 12, December 2015}




\section{International Journal of Science and Research (IJSR) \\ ISSN (Online): 2319-7064}

Index Copernicus Value (2013): 6.14 | Impact Factor (2014): 5.611

Theorem 5. $S_{n} \oplus K_{1, n}$ is prime graph, for all $n \in N$.

Proof. Let $\mathrm{V}(\mathrm{G})=\mathrm{V}_{1} \cup \mathrm{V}_{2}$, where $\mathrm{V}_{1}=\left\{\mathrm{u}_{1}, \mathrm{u}_{2}, \ldots, \mathrm{u}_{\mathrm{n}}\right\}$ with apex $u_{1}$ and $u_{2}, u_{3}, \ldots, u_{n}$ are other vertices of $S_{n}$ and $V_{2}$ $=\left\{\mathrm{v}=\mathrm{u}_{1}, \mathrm{v}_{1}, \mathrm{v}_{2}, \ldots, \mathrm{v}_{\mathrm{n}}\right\}$ be the vertex set of $\mathrm{K}_{1, \mathrm{n}}$. Here $\mathrm{v}_{1}, \mathrm{v}_{2}$, $\ldots, \mathrm{V}_{\mathrm{n}}$ are pendent vertices.

We define labeling $\mathrm{f}: \mathrm{V}(\mathrm{G}) \rightarrow\{1,2,3, \ldots, 2 \mathrm{n}\}$ as follows

$\mathrm{f}\left(\mathrm{u}_{\mathrm{i}}\right)=2 \mathrm{i}-1 ; 1 \leq \mathrm{i} \leq \mathrm{n}$

$\mathrm{f}\left(\mathrm{v}_{\mathrm{j}}\right)=2 \mathrm{j} ; 1 \leq \mathrm{j} \leq \mathrm{n}$

According to this pattern the vertices are labeled such that for any edge $\mathrm{e}=\mathrm{u}_{\mathrm{i}} \mathrm{u}_{\mathrm{j}} \in \mathrm{G}$,

$\operatorname{gcd}\left(f\left(u_{i}\right), f\left(u_{j}\right)\right)=1$.

Thus we proved that the graph under consideration admits prime labeling.

That is, $S_{n} \oplus K_{1, n}$ is a prime graph.

Example 5. prime labeling of the graph $S_{7} \oplus K_{1,7}$ is shown in Fig. 5 as an illustration for the Theorem 5.

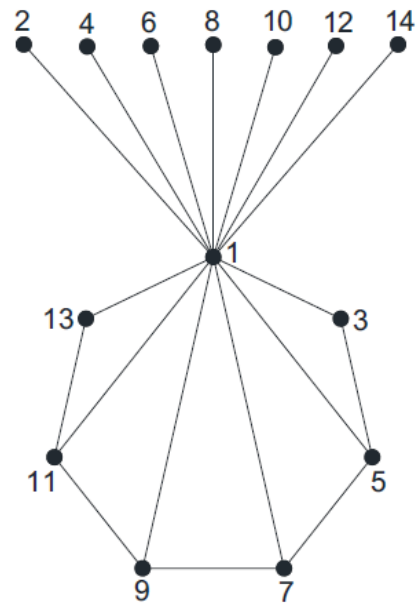

Figure 5: prime labeling of the graph $\mathrm{S}_{7} \oplus \mathrm{K}_{1,7}$

\section{Conclusion}

We have proved that the graph $\mathrm{Cn} \oplus \mathrm{K}_{1}, \mathrm{n}, \mathrm{G} \oplus \mathrm{K}_{1}, \mathrm{n}$, where $\mathrm{G}$ is cycle with one chord, $\mathrm{G} \oplus \mathrm{K}_{1}, \mathrm{n}$, where $\mathrm{G}$ is cycle with twin chord, $G \oplus K_{1}, n$, where $G$ is cycle with triangle, $\mathrm{Sn} \oplus$ $\mathrm{K}_{1}, \mathrm{n}$ are prime graphs.

\section{References}

[1] J. A. Gallian, "A dynamic survey of graph labeling", The Electronics Journal of Combinatorics, 16(2013), DS 61 308.

[2] J. Gross and J. Yellen, Graph Theory and its Applications, CRC Press, 1999.

[3] A. Tout, A. N. Dabboucy, and K. Howalla, Prime labeling of graphs, Nat. Acad. Sci. Letters, 11(1982), 365 - 368

[4] P. Haxell, O. Pikhurko, and A. Taraz, Primality of trees J. Combinatorics, 2(2011), $481-500$.

[5] M. A. Seoud, A. T. Diab, and E. A. Elsahawi, On strongly-C harmonious, relatively prime, odd graceful and cordial graphs, Proc. Math. Phys. Soc. Egypt, no. 73(1998), $33-55$.

[6] S. K. Vaidya and U. M. Prajapati, Prime labeling in the context of duplication of graph elements, Internat. J. Math. Soft Comput., 3(1), (2013), 13 - 20.

[7] M. Z. Youssef and E.A. El Sakhawi, Some properties of prime graphs, Ars Combin., 84(2007), 129 - 140.

\section{Author Profile}

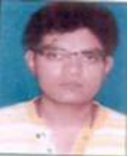

Mr. Amit H. Rokad received M.Sc. degree from M. S University, Baroda, (Gujarat) in 2009. Currently he is working as an assistant professor in Mathematics at School of Technology, R.K. University. He is doing his Ph.D. under the guidance of Dr. G. V. Ghodasara at R.K. University, Rajkot.

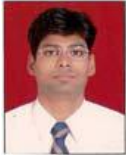

Dr. Gaurang V. Ghodasara received M.Sc. degree from Sardar Patel University, Vallabh Vidyanagar, (Gujarat). He received M. Phil and Ph. D. both degree from Saurashtra University, Rajkot(Gujarat) in 2005 and 2009 respectively. He worked as an assistant professor in Mathematics Department at Atmiya Institute of Technology \& Science, Rajkot and L. E. College Morbi. Currently he is working as an assistant professor in Mathematics Department at H. \& H. B. Kotak Institute of Science, Rajkot(Gujarat). He is registered guide at R.K. University, Rajkot. 